\title{
A Construção Civil em Minas Gerais: Caracterização Geral, Concentração Industrial, Barreiras à Entrada e Desempenho Econômico*
}

\section{The Construction Industry in Minas Gerais State: Overall View, Market Concentration Degree, Barriers to Entry and Economic Performance}

Luciene Pires Teixeira** Marcelo José Braga***

Resumo: O presente artigo objetiva analisar aspectos da estrutura industrial da construção civil em Minas Gerais. Em particular, investiga-se a concentração de mercado e a margem preço-custo, com vistas a entender a dinâmica competitiva setorial no período mais recente. O conhecimento da organização industrial do setor é importante para a atuação das empresas já existentes e para as potencialmente entrantes no mercado, como também para a intervenção governamental, por meio de políticas públicas mais adequadas à realidade das atividades construtivas locais. O estudo baseia-se no paradigma Estrutura-Conduta-Desempenho e utiliza o método empírico proposto por McCloughan e Abounoori (2003) para estimar a concentração industrial. São fornecidas evidências empíricas sobre o grau e a evolução da concentração de mercado por segmento de atividade componente no período 1996-2005. Os resultados obtidos apontam para um elevado grau de concentração na construção civil mineira e ganhos de lucratividade no período.

Palavras-chave: Concentração de mercado. Barreiras à entrada. Desempenho econômico.

Abstract: The present article aims to analyze some aspects of civil construction industrial structure in Minas Gerais state, investigating its market concentration degree and the competitive dynamics of the sector in recent period. It is assu-

\footnotetext{
* $\quad$ Os autores agradecem os valiosos comentários e sugestões de um parecerista anônimo.

* * Master in Economics, New School for Social Research (NY - USA). Doutoranda em Economia Aplicada pela Universidade Federal de Viçosa (UFV). E-mail: lucienepteixeira@gmail.com

*** Engenheiro Agrônomo, D.S. Economia Rural, Pós-Doctor em Economia de Organizações Cooperativas, Universidade da Califórnia (USA). E-mail: mjbraga@ufv.br
} 
med that knowledge on the sector industrial organization is important to the performance of already existing companies and potentially entering ones in the market, as well as to governmental intervention by means of public policies more suitable to local constructive activities reality. The study is based on the Structure-Conduct-Performance paradigm and uses McCloughan e Abounoori (2003) method to bring out the degree and evolution of market concentration of civil construction and its components during 1996-2005. The estimated results point out to high degree of concentration in Minas Gerais civil construction as well as gains in profitability in the analised time period.

Keywords: Market concentration. Barriers to entry. Economic performance.

JEL Classification: L74; L11.

\section{1 lntrodução}

Em muitos países, a indústria de construção civil é reconhecida como atividade essencial para o desenvolvimento econômico, conforme atestam estudos internacionais, cabendo citar alguns como Myers (2004), Lean (2001), Hillebrandt (2000), Finkel (1997), Ofori (1990), Polenske e Sivitanides (1989). O papel influente da construção como vetor do crescimento econômico é usualmente mensurado pelo tamanho relativo do seu produto como proporção da renda nacional, por sua ampla rede de ligações setoriais e elevado efeito multiplicador de emprego, com profundas repercussões socioeconômicas locais.

No Brasil, há poucas contribuições analíticas sobre o setor. A Fundação João Pinheiro - FJP - (1984) elaborou um diagnóstico detalhado sobre a construção civil brasileira na década de 70, e o estudo de Chaves (1985) está focado na dinâmica e no processo de desenvolvimento setorial, atendo-se aos anos 70 e ao início dos 80. Teixeira e Carvalho (2005) analisaram a construção brasileira no período mais recente, destacando suas interligações com outras atividades econômicas e seus efeitos de transbordamento sobre a produção, a renda, o emprego e os tributos nacionais, concluindo que esta é uma indústria-chave para o desenvolvimento do país. Porém, a literatura consultada indica que poucos trabalhos se preocupam em estudar a indústria da construção civil no estado de Minas Gerais. Silva (2007) dimensionou e analisou o cluster da construção mineira dentro da matriz insumo-produto estadual de 1996, mas sua preocupação central foi identificar as características de toda a cadeia produtiva da construção, os atributos e a forma de organização de suas empresas, com ênfase na análise das suas práticas de gestão do conhecimento e no nível de desenvolvimento das suas redes de informações e inovações. Questões que envolvem as caracte- 
rísticas e a organização industrial da construção civil em Minas Gerais são relevantes e precisam ser analisadas com referência aos anos mais recentes, notadamente de 90 em diante.

Estudos internacionais sugerem que a estrutura industrial da construção civil é desconcentrada. Tal resultado aparece, por exemplo, em McCloughan (2004) que estimou a concentração no setor de construção da Inglaterra e Toner (2000) que analisou as mudanças na estrutura industrial da construção australiana. Os dados do Cadastro Central de Empresas (IBGE, 2005) confirmam este argumento para o caso do Brasil, ao apresentar os indicadores de concentração econômica em relação à variável pessoal ocupado total das maiores empresas da construção tanto no agregado quanto por grupo da classificação de atividades, para o ano de 2005. Tomando a participação da variável pessoal ocupado nas quatro, oito e doze maiores empresas, os valores encontrados para o total da construção nacional foram de 2,78\%, 4,42\% e 5,71\%, respectivamente, indicando baixa concentração de mercado. As estimativas calculadas por Teixeira (2009), também no caso da construção brasileira, sugerem que a estrutura deste segmento industrial é desconcentrada, implicando elevado grau de competição ou concorrência no mercado. Librelotto, Ferroli e Rados (2003), ao estudarem a sustentabilidade das empresas de construção civil nas dimensões econômica, social e ambiental, também apontam nesta direção. Mas há que investigar se estas mesmas características estruturais prevalecem no caso da construção mineira e analisar a dinâmica do seu desempenho econômico, justificando esse esforço de pesquisa. Há carência de estudo mais recente que retrate as mudanças estruturais e dimensione o grau de concentração industrial neste mercado, bem como avalie o seu desempenho econômico, uma vez que os estudos da FJP (1984) e de Chaves (1985) abordam o tema para as décadas de 70 e 80 do século XX.

Seguindo a hipótese do poder de mercado estabelecida no paradigma Estrutura-Conduta-Desempenho, uma elevada concentração de mercado é algo não desejável, do ponto de vista social, e deveria ser evitada. A existência de estruturas industriais muito concentradas pode ser um bom indicativo de baixo grau de competição e ineficiências alocativas, exigindo a intervenção governamental, para evitar abusos do poder econômico por parte das firmas atuantes no mercado. Poder econômico excessivo acarreta dominação de mercados e prejuízos para toda a sociedade. Daí a importância de monitorar os fatores condicionantes da organização de uma determinada indústria, em particular a construção civil, que é considerada estratégica para o desenvolvimento socioeconômico regional. 
Frequentemente grandes projetos de construção civil - financiados com recursos públicos - são usados como forma de incrementar a demanda agregada em períodos recessivos ou mesmo como apelo político, dada a alta participação setorial no produto agregado e seu elevado efeito multiplicador de renda e emprego. Além disto, a demanda do setor é diretamente dependente da existência de fundos públicos direcionados, condições favoráveis de crédito a longo prazo, políticas de juros e incentivos tributários. Desta forma, a indústria da construção civil merece estudos mais específicos que ajudem a lançar novas perspectivas para as políticas públicas voltadas para o setor e para as estratégias de desenvolvimento estadual. As autoridades governamentais de Minas Gerais precisam estar cientes das características estruturais deste setor industrial no estado nos anos mais recentes.

O presente estudo, além de descrever as principais características da construção civil em Minas Gerais, objetiva discutir aspectos da sua organização industrial, notadamente no que diz respeito à concentração de mercado e desempenho econômico. A fundamentação teórica é o modelo Estrutura-Conduta-Desempenho (E-C-D), que assume que as estratégias empresarias são decorrentes da estrutura de mercado e determinam o desempenho econômico do mesmo.

O texto está dividido em cinco partes, incluindo esta introdução. A segunda seção posiciona a construção civil na economia mineira, ressaltando a caracterização setorial para os anos mais recentes, sua participação direta na produção e capacidade de geração de empregos. $\mathrm{Na}$ terceira seção, discute-se a metodologia e as fontes de dados que embasam os resultados estimados. A quarta seção apresenta as estimativas para as medidas de concentração de mercado e de desempenho econômico, discute a diferenciação de produtos e barreiras à entrada, bem como suas principais implicações para o setor. E, finalmente, a quinta seção destaca as conclusões deste estudo, com algumas ponderações gerais sobre o setor e suas repercussões para o desenvolvimento socioeconômico do estado de Minas Gerais.

\section{Características Gerais da Construção Civil Mineira}

\subsection{Produção, Composição Estrutural e Geração de Emprego}

A construção civil é uma atividade importante na estrutura produtiva da economia mineira. Na média dos últimos quinze anos, o setor contribuiu com quase $11 \%$ para o valor adicionado total do estado. Este percentual, próximo das estatísticas encontradas nos países mais desenvolvidos, está bem acima do correspondente para a construção 
nacional (6,32\%) e qualifica as atividades de construção como relevantes para a economia estadual. Considerando-se a evolução de quase toda a série histórica, a participação direta do setor mineiro sobrepassa a nacional, ficando aquém apenas no ano de 1993. Conforme atestam os dados da Tabela 1, em 2004, o setor movimentou na economia de Minas Gerais quase $\mathrm{R} \$ 15$ bilhões e sua produção contribuiu com $24 \%$ para o total do valor adicionado pela indústria estadual. Neste mesmo ano, a construção mineira ocupou a $3^{a}$ posição no ranking das principais atividades econômicas estaduais, junto com as atividades imobiliárias, os aluguéis e os serviços prestados às empresas, só perdendo para a indústria de transformação e para a administração pública, defesa e seguridade social.

O crescimento do setor em Minas Gerais apresenta relativa aderência com o nacional, com taxas anuais oscilando pouco acima da média nacional nas duas últimas décadas, e também acompanha a trajetória do produto estadual. Mantendo o mesmo desempenho abaixo do produto agregado mineiro, o setor acumulou queda de $9,91 \%$ nos últimos quatro anos. A taxa de crescimento observada em 2004 (1,38\%) foi a melhor performance setorial desde o ano 2000, na esteira do crescimento real de $4,51 \%$ da economia estadual, conforme informações da Tabela 1.

Tabela 1 - Valor Adicionado (VA) Total e Valor Adicionado (VA) da Construção - Minas Gerais - 1990 a 2004 (em R \$ milhões)

\begin{tabular}{|c|c|c|c|c|c|}
\hline \multirow[b]{2}{*}{ Ano } & \multicolumn{2}{|c|}{ VA - TOTAL } & \multicolumn{2}{|c|}{ VA - CONSTRUÇÃO } & \multirow{2}{*}{$\begin{array}{l}\text { Participação do } \\
\text { VA da Constru- } \\
\text { ção no VA de MG } \\
\text { (em \%) }\end{array}$} \\
\hline & $\begin{array}{l}\text { A preço } \\
\text { corrente }\end{array}$ & $\begin{array}{l}\text { taxa de } \\
\text { crescimento }\end{array}$ & $\begin{array}{l}\text { A preço } \\
\text { corrente }\end{array}$ & $\begin{array}{l}\text { Taxa de } \\
\text { crescimento }\end{array}$ & \\
\hline 1990 & 1,03 & - & 0,092250 & - & 8,93 \\
\hline 1991 & 5,53 & 2,53 & 0,457259 & 3,92 & 8,26 \\
\hline 1992 & 63,04 & $-2,09$ & 5,257007 & $-5,77$ & 8,34 \\
\hline 1993 & $1.480,85$ & 4,23 & 117,1231 & $-0,46$ & 7,91 \\
\hline 1994 & 34.771 & 5,55 & 3.488 & 5,74 & 10,03 \\
\hline 1995 & 58.882 & 3,16 & 6.900 & 7,75 & 11,72 \\
\hline 1996 & 73.727 & 5,42 & 9.178 & 13,05 & 12,45 \\
\hline 1997 & 82.126 & 3,66 & 10.959 & 7,23 & 13,34 \\
\hline 1998 & 84.216 & 0,59 & 11.085 & $-1,46$ & 13,16 \\
\hline 1999 & 87.491 & 1,62 & 11.265 & 1,74 & 12,88 \\
\hline 2000 & 98.867 & 5,09 & 12.695 & 2,71 & 12,84 \\
\hline 2001 & 105.094 & 0,09 & 12.280 & $-3,16$ & 11,68 \\
\hline 2002 & 117.890 & 2,61 & 12.828 & $-2,16$ & 10,88 \\
\hline 2003 & 135.909 & 0,48 & 13.317 & $-6,21$ & 9,80 \\
\hline 2004 & 156.176 & 4,51 & 14.825 & 1,38 & 9,49 \\
\hline
\end{tabular}

Fonte: Elaboração da autora a partir das Contas Regionais do IBGE (2004). 
As atividades de construção em Minas Gerais têm peso significativo também na composição do valor adicionado pela construção nacional. Com participação de 14,6\% na média dos últimos 15 anos, o setor mineiro ocupa a $2^{\mathrm{a}}$ posição vis-à-vis as demais unidades da federação, atrás somente da construção paulista, cuja contribuição é de 31,2\% no mesmo período.

Conceitualmente, a construção civil é considerada um setor multiproduto, dada a grande diversidade dos seus produtos e serviços finais, bem como a natureza variada das suas operações industriais. A heterogeneidade na sua estrutura produtiva reflete-se nas especificidades de cada um dos seus segmentos de atividades, que possuem diferentes composições no valor adicionado setorial e impactos diversos na geração de emprego, conforme dados da Tabela 2.

Tabela 2 - Produção, Consumo Intermediário das Atividades, Valor Adicionado e Emprego, para a Construção e seus subsetores - Minas Gerais 01996 (em R\$ mil)

\begin{tabular}{|c|c|c|c|c|c|c|}
\hline $\begin{array}{l}\text { Compo- } \\
\text { nentes do } \\
\text { Valor Adi- } \\
\text { cionado }\end{array}$ & Construção & $\begin{array}{l}\text { Prepa- } \\
\text { ração do } \\
\text { terreno }\end{array}$ & $\begin{array}{l}\text { Construção } \\
\text { de edifí- } \\
\text { cios (inclui } \\
\text { instalações e } \\
\text { acabamentos) }\end{array}$ & $\begin{array}{l}\text { Constru- } \\
\text { ção de } \\
\text { obras de } \\
\text { engenha- } \\
\text { ria civil }\end{array}$ & $\begin{array}{l}\text { Obras de infra- } \\
\text { estrutura para } \\
\text { engenharia elé- } \\
\text { trica e de tele- } \\
\text { comunicações }\end{array}$ & $\begin{array}{l}\text { Construção } \\
\text { por traba- } \\
\text { lhadores } \\
\text { autônomos }\end{array}$ \\
\hline $\begin{array}{l}\text { Total do } \\
\text { Consumo } \\
\text { Interme- } \\
\text { diário }\end{array}$ & 7.691 .338 & 353.911 & 2.857 .057 & 2.901 .345 & 1.424 .334 & 154.692 \\
\hline $\begin{array}{l}\text { Valor Adi- } \\
\text { cionado } \\
\text { Bruto }\end{array}$ & 8.820 .082 & 360.676 & 2.943 .846 & 3.582 .958 & 1.430 .036 & 502.566 \\
\hline $\begin{array}{l}\text { Remune- } \\
\text { rações + } \\
\text { rendi- } \\
\text { mento dos } \\
\text { autônomos }\end{array}$ & 1.534 .649 & 45.455 & 426.979 & 364.288 & 228.686 & 469.241 \\
\hline $\begin{array}{l}\text { Demais } \\
\text { elementos } \\
\text { do Valor } \\
\text { Adicio- } \\
\text { nado }\end{array}$ & 7.285 .432 & 250.675 & 1.995 .803 & 2.689 .528 & 941.583 & 5.112 \\
\hline $\begin{array}{l}\text { Pessoal } \\
\text { ocupado } \\
\text { (em } \\
\text { número de } \\
\text { pessoas) }\end{array}$ & 549.973 & 15.970 & 171.467 & 107.391 & 73.250 & 181.896 \\
\hline $\begin{array}{l}\text { Valor da } \\
\text { Produção }\end{array}$ & 16.511 .419 & 714.586 & 5.800 .903 & 6.484 .302 & 2.854 .370 & 657.257 \\
\hline
\end{tabular}

Fonte: Elaboração da autora a partir da matriz do macrossetor da construção para 1996, elaborada por Silva (2006). 
Isoladamente, as obras de engenharia civil concentram a maior parcela do valor da produção e do valor adicionado setorial (39,3\% e 40,6\%, respectivamente), mas ocupam menos de $20 \%$ da mão de obra empregada. Este segmento é, por força de suas atividades e características específicas dos seus produtos finais, mais intensivo em máquinas e equipamentos, o que justifica o menor uso de capital humano. As obras de edificações, instalações e acabamentos assumem a segunda posição na dinâmica da produção setorial, porém são as atividades com a maior parcela do pessoal ocupado $(31,2 \%)$. Tomados em conjunto, os dois subgrupos perfazem mais de $74 \%$ do valor da produção e quase $51 \%$ do fator trabalho.

Segundo o Cadastro Central de Empresas (IBGE, 2005), a construção de edifícios (não incluindo as obras de instalação e acabamentos) e as obras de engenharia civil registraram, em 2005, 8.747 empresas formalizadas, que ocuparam 123.522 trabalhadores e pagaram salários correspondentes a $\mathrm{R} \$ 917,5$ milhões, conforme mostram os dados da Tabela 3. No agregado, a indústria construtiva mineira operou com 13.113 unidades de produção (quase 10\% do total de estabelecimentos da construção nacional), sendo responsáveis pela ocupação de $12 \%$ do total da mão de obra formal que o setor ocupou em âmbito nacional (1.473.272 trabalhadores).

Tabela 3 - Número de empresas, pessoal ocupado total e salários/outras remunerações (em R\$ mil), segundo grupos da classificação de atividades da Construção, em Minas Gerais - 1996 a 2005

\begin{tabular}{|c|c|c|c|c|c|c|c|c|c|c|}
\hline $\begin{array}{l}\text { Classificação } \\
\text { da atividade e } \\
\text { grupos }\end{array}$ & 1996 & 1997 & 1998 & 1999 & 2000 & 2001 & 2002 & 2003 & 2004 & 2005 \\
\hline \multicolumn{11}{|l|}{ Construção } \\
\hline $\mathbf{N}^{\circ}$ de empresas & 9.859 & 10.540 & 11.138 & 11.345 & 11.674 & 12.996 & 12.909 & 12.672 & 12.662 & 13.113 \\
\hline Pessoal Ocupado & 132.970 & 151.231 & 132.554 & 124.954 & 139.405 & 159.424 & 160.984 & 151.768 & 160.805 & 177.017 \\
\hline $\begin{array}{l}\text { Salários/remune- } \\
\text { raçôes (R\$ mil) }\end{array}$ & 568.120 & 761.217 & 707.272 & 561.270 & 709.502 & 965.217 & 1.002 .445 & 1.062 .526 & 1.290 .678 & 1.362 .807 \\
\hline \multicolumn{11}{|c|}{ Preparação do terreno } \\
\hline $\mathbf{N}^{\circ}$ de empresas & 675 & 685 & 727 & 787 & 844 & 962 & 1.012 & 1.032 & 1.053 & 1.062 \\
\hline Pessoal ocupado & 10.596 & 8.263 & 8.518 & 7.192 & 8.196 & 9.050 & 11.508 & 10.395 & 13.791 & 14.331 \\
\hline $\begin{array}{l}\text { Salários/remune- } \\
\text { raçôes (R\$ mil) }\end{array}$ & 63.568 & 31.033 & 50.753 & 30.881 & 40.363 & 47.972 & 61.979 & 62.700 & 173.744 & 106.960 \\
\hline \multicolumn{11}{|c|}{ Construção de edifícios e obras de engenharia civil } \\
\hline$N^{\circ}$ de empresas & 5.729 & 6.079 & 6.421 & 6.650 & 6.927 & 7.851 & 8.724 & 8.537 & 8.481 & 8.747 \\
\hline Pessoal ocupado & 93.898 & 109.702 & 87.943 & 82.306 & 89.218 & 109.686 & 106.771 & 101.548 & 114.504 & 123.522 \\
\hline
\end{tabular}


(continuação)

\begin{tabular}{|c|c|c|c|c|c|c|c|c|c|c|}
\hline $\begin{array}{l}\text { Salários/remu- } \\
\text { nerações (R\$ } \\
\text { mil) }\end{array}$ & 390.625 & 601.669 & 502.065 & 369.934 & 445.777 & 652.060 & 602.654 & 631.960 & 860.122 & 917.473 \\
\hline bras de infraest & trutura & para en & ergia el & étrica $\mathbf{e}$ & para tel & ecomun & nicações & & & \\
\hline$N^{\circ}$ de empresas & 209 & 236 & 239 & 262 & 296 & 368 & 391 & 302 & 300 & 310 \\
\hline Pessoal ocupado & 9.602 & 13.849 & 14.035 & 15.846 & 21.311 & 18.992 & 19.486 & 15.984 & 9.970 & 12.013 \\
\hline $\begin{array}{l}\text { Salários/remu- } \\
\text { nerações (R\$ } \\
\text { mil) }\end{array}$ & 51.814 & 74.960 & 84.646 & 98.334 & 149.120 & 181.977 & 197.770 & 218.051 & 101.168 & 137.128 \\
\hline Obras de instalaç & ções & & & & & & & & & \\
\hline $\mathbf{N}^{\circ}$ de empresas & 1.040 & 1.097 & 1.208 & 1.169 & 1.236 & 1.368 & 1.542 & 1.504 & 1.483 & 1.469 \\
\hline Pessoal ocupado & 7.632 & 6.496 & 9.267 & 7.799 & 8.626 & 9.768 & 16.167 & 16.686 & 13.221 & 14.566 \\
\hline $\begin{array}{l}\text { Salários/remu- } \\
\text { nerações (R\$ } \\
\text { mil) }\end{array}$ & 28.472 & 19.918 & 33.820 & 29.752 & 36.404 & 49.680 & 111.316 & 119.414 & 93.187 & 106.742 \\
\hline Obras de acabam & nento & & & & & & & & & \\
\hline $\mathbf{N}^{\circ}$ de empresas & 2.137 & 2.370 & 2.466 & 2.404 & 2.288 & 2.354 & 1.115 & 1.161 & 1.202 & 1.362 \\
\hline Pessoal ocupado & 10.805 & 12.346 & 12.133 & 11.413 & 11.669 & 11.429 & 5.986 & 5.626 & 5.427 & 8.355 \\
\hline $\begin{array}{l}\text { Salários/remu- } \\
\text { nerações (R\$ } \\
\text { mil) }\end{array}$ & 32.455 & 31.768 & 33.741 & 31.064 & 36.482 & 31.277 & 20.538 & 20.300 & 21.261 & 41.683 \\
\hline Aluguel de equip & bamento & s de cor & nstruçã & o e dem & olição c & om ope & rários & & & \\
\hline $\mathbf{N}^{\circ}$ de empresas & 69 & 73 & 77 & 73 & 83 & 93 & 125 & 136 & 143 & 163 \\
\hline Pessoal ocupado & 437 & 575 & 658 & 398 & 385 & 499 & 1.066 & 1.529 & 3.892 & 4.230 \\
\hline $\begin{array}{l}\text { Salários/remu- } \\
\text { nerações (R\$ } \\
\text { mil) }\end{array}$ & 1.186 & 1.869 & 2.247 & 1.305 & 1.356 & 2.251 & 8.188 & 10.101 & 41.196 & 52.822 \\
\hline
\end{tabular}

Fonte: Elaboração da autora a partir do Cadastro Central de Empresas - Banco de Dados Sidra - IBGE.

É grande a capacidade setorial para a criação de empregos na economia estadual. Pelos dados da matriz de Minas Gerias para 1996 (SILVA, 2007), o setor ocupa diretamente quase $9 \%$ do fator trabalho na economia estadual. A construção tem efeito significativo sobre o nível de emprego porque suas atividades são, em geral, de mão de obra intensivas. Dados da Pesquisa Nacional por Amostras em Domicílios - PNAD - (IBGE, 2006), que considera os mercados de trabalho formal e informal, mostram que em 2006 a construção civil em Minas Gerais ocupou 743 mil pessoas, quase $7 \%$ do total do pessoal economicamente ativo e ocupado pelo conjunto das atividades no estado. No quesito utilização de mão de obra, verifica-se que a construção mineira é a sexta atividade no ranking estadual e se equipara ao desempenho do setor em nível nacional. A despeito de uma performance econômica fraca, em especial a partir de 
1998, a indústria construtiva estadual vem conseguindo manter o nível de emprego.

A informalidade é um ponto a ser salientado na caracterização da construção em Minas Gerais. Estudo do IBGE (2003) destaca o setor como o segundo em número de empresas do mercado informal no estado, perdendo apenas para as atividades de comércio e reparação. Ao todo são 213.927 unidades de produção não legalizadas, das quais 55.584 trabalham por encomenda ou subcontrato, e 13.377 são estabelecimentos empregadores que ocupam de uma a mais de três pessoas, informalmente.

Esses aspectos estruturais da construção civil mineira ratificam sua grande influência na promoção do crescimento econômico e geração de emprego em Minas Gerais. Mas, conforme ressaltam Carneiro e Valpassos (2003), a reconhecida importância do setor da construção civil supera o aspecto meramente econômico de multiplicador de renda e emprego, dada sua expressiva função social na economia, qual seja, de empregar mais trabalhadores pertencentes às faixas de baixa renda e ampliar o bem-estar social via mitigação dos graves problemas de déficit habitacional, de saneamento básico e de infraestrutura básica que provocam profundas consequências na desorganização econômico-social do país. Tais reflexões devem permear as discussões sobre a dinâmica competitiva do setor. O notório impacto econômico e social da construção civil mineira justifica, por si só, uma preocupação com o nível de concorrência e desempenho econômico de suas empresas, que pode refletir, dentre outras ocorrências, em mudanças na capacidade de absorção da mão de obra e na composição disponível de sua qualificação. Além disso, há uma clara interação entre o nível de competição de um setor e a perda de bem-estar social e conhecê-la pode ser útil às autoridades governamentais, quando da elaboração de políticas públicas e alocação de recursos a setores considerados prioritários.

\section{Metodologia}

\subsection{Referencial Teórico}

O paradigma Estrutura-Conduta-Desempenho (E-C-D) é uma ferramenta analítica importante quando se pretende discutir as especificidades estruturais de um setor e estudar a competitividade de suas empresas no mercado. O modelo E-C-D ressalta a estrutura do mercado (concentração industrial) como a principal fonte de poder de mercado das empresas, refletindo em seu desempenho competitivo (rentabilidade). No conceito 
de estrutura, estão as configurações estratégicas que podem descrever uma determinada indústria ou mercado. Para Bain (1959) e Martin (1993), existem pelo menos três elementos que definem a estrutura de mercado: i) grau de concentração; ii) diferenciação de produtos e iii) barreiras à entrada de novas firmas. Assim, um dado mercado pode ser descrito pelo número de empresas participantes, que condiciona o grau de concentração e o poder de mercado; pelo grau de homogeneidade do produto e pela liberdade de entrada e saída de novos concorrentes. Os elementos de composição da estrutura determinam as práticas empresariais em termos de fixação de preços, política de vendas, qualificação do produto, propaganda e marketing, dentre outras. Por sua vez, a conduta das empresas repercute no desempenho econômico (crescimento e lucratividade) e na eficiência alocativa dos recursos.

Ou seja, o pressuposto básico do paradigma Estrutura-CondutaDesempenho é que as condições estruturais refletem sobre a performance e a eficiência do mercado, supondo que as condutas das firmas atuantes sejam fortemente influenciadas pelos parâmetros estruturais vigentes. Assim a análise das variáveis-chave que descrevem a estrutura são informações importantes que auxiliam no estudo da organização de uma indústria e do seu desempenho econômico.

Um mercado com muitas firmas, produto sem diferenciação e liberdade de entrada e saída de participantes é tido como mais competitivo, justamente porque as firmas têm pouca margem para estratégias (de preços/vendas) e buscam a sobrevivência econômica via redução de custos. A expectativa neste tipo de mercado é de que a produção fique num patamar próximo ao nível que seria produzido em condições de competição perfeita. Por outro lado, em mercados mais concentrados, com produtos diferenciados e barreiras à entrada de novos concorrentes, as firmas tendem a agir taticamente para manter e incrementar os lucros, produzindo quantidades próximas à da produção em monopólio, o que resulta em desempenho insatisfatório.

O conceito de barreiras à entrada, desenvolvido a partir das contribuições teóricas de Bain (1959) e Sylos-Labini (1956), é também elemento importante para a análise da estrutura de um mercado, na medida em que auxilia na avaliação do desempenho econômico de uma indústria específica. Conforme destacam Possas et al. (1998), "[...] verifica-se que a presença de um baixo nível de barreiras à entrada em um mercado relevante - ou seja, a existência de forte concorrência potencial - é suficiente para impedir o surgimento e/ou o exercício de poder de mercado por parte de empresas". Em contraposição, mercados com fortes impedimentos à entrada de novos concorrentes podem conduzir a situações de elevação abusiva de margens de lucro e prejuízos para os consumidores. 
A "condição de entrada", na terminologia de Bain (1959), em determinada indústria ocorre quando as firmas já estabelecidas possuem vantagens sobre os competidores potenciais, sendo que essas vantagens se refletem na capacidade de elevar persistentemente seus preços acima do custo médio de longo prazo, obtendo lucro extraordinário, sem induzir a entrada de novas firmas no mercado. As empresas consideradas potenciais entrantes possuem desvantagens em relação às já estabelecidas no mercado, devido a fatores - denominados fontes de barreiras à entrada - que podem ser divididos em três categorias: a) vantagens absolutas de custos; b) diferenciação do produto e c) economias de escala.

Ou seja, em mercados concentrados, com barreiras à entrada e pouco competitivos, as empresas têm poder de mercado e conseguem manter o preço acima do custo médio, obtendo margens de lucros abusivas (lucros econômicos positivos, mesmo no longo prazo). O resultado é um nível de produção abaixo do socialmente desejável, custos unitários maiores, preços mais elevados que os competitivos, redundando em desempenho alocativo ineficiente, prejuízo para os consumidores e distribuição não equitativa da renda.

Conforme esclarece Zeidan (2005), a abordagem E-C-D tem sido foco de muitas críticas, formuladas, dentre outras, pelos proponentes da New Empirical Industrial Organization - NEIO. Os teóricos da NEIO argumentam que as medidas de concentração pouco refletem o poder de mercado de uma indústria, já que não levam em conta as elasticidades neste mercado. Ademais, as informações corretas sobre custos variáveis/ marginais podem não existir ou são limitadas, pela indisponibilidade de dados, além da pouca confiabilidade de usar dados contábeis e da dificuldade para observar as características estruturais nas diversas indústrias, de modo que os resultados apresentados pelo modelo E-C-D podem conter viés estimativo para medir o desempenho das indústrias. Em contraposição, o poder de mercado deve ser estimado através de parâmetros que identificam a conduta das firmas. Assumindo-se que os custos marginais são não observáveis, as condutas estratégicas das firmas são analisadas através de modelos que estimam suas elasticidades de demanda, destacando o comportamento nos diferentes mercados a partir de dados observados de preço e quantidade de equilíbrio. Também como contraponto à abordagem E-C-D, a Escola de Chicago ${ }^{1}$ argumenta que as empresas maiores se beneficiam de economias de escala e escopo, trazendo ganhos de eficiência para a economia. Neste caso, a ausência de barreiras à entrada atrairia os concorrentes, caso houvesse qualquer ineficiência.

$\overline{1}$ Veja em Martin (1993), discussão comparativa entre as duas abordagens. 
As argumentações contrárias ao modelo E-C-D não o invalidam como instrumental de análise em termos de organização industrial, que prevalece sendo importante ferramenta nas decisões de políticas antitruste. As disputas teóricas entre os proponentes da escola tradicional e da NEIO, como em qualquer outro ramo da economia, são parte do processo de desenvolvimento da ciência e embasam posições contrárias no que tange à intervenção governamental na economia e, em particular, ao papel do governo na melhora da performance de mercado.

\subsection{Procedimento Analítico}

No paradigma E-C-D, o grau de concentração de uma indústria é o elemento básico da estrutura e o indicador-chave quando se pretende identificar o poder de mercado, pois considera tanto o número quanto o tamanho das firmas atuantes na indústria. Dentre os vários índices de concentração, a razão de concentração $(\mathrm{CRn})$ é o método mais comumente empregado para analisar a estrutura de mercado, podendo ser facilmente calculada com base em informações sobre emprego, faturamento, vendas, capacidade instalada, dentre outras variáveis disponíveis, para as $m$ empresas no mercado, em que as $n$ primeiras firmas $(1,2,3 \ldots n)$ são as que possuem as maiores participações de mercado (market shares). A razão de concentração é determinada de acordo com a equação (1):

$$
C R n=\sum_{i=1}^{n} B i
$$

Em que:

$$
B i=\frac{Q i}{\sum_{i=1}^{m} Q i}
$$

A equação (2) representa o market share da empresa i. Quanto maior o CRn, maior o poder de mercado na indústria em análise.

Conforme destaca Teixeira (2009), em se tratando da indústria de construção civil, "[...] o inconveniente para o cálculo da razão de concentração é a ausência de dados desagregados e individualizados para todas as empresas participantes do mercado". McCloughan e Abounoori (2003) propõem uma solução, nestes casos, ao apresentarem um método para medir a concentração de mercado para dados agrupados, quando o número total das empresas e sua proporção do market share (medido por uma variável de análise específica) só estão disponibilizados em intervalos de classes. 
O método proposto por McCloughan e Abounoori (2003) pode ser expresso pelas seguintes equações:

$$
\begin{gathered}
C R k=1-\left[F 1(x j-1)+\left\{\left(1-\frac{k}{n}\right)-F(x j-1)\right\} *\left\{\frac{F 1(x j)-F 1(x j-1)}{F(x j)-F(x j-1)}\right\}\right] \\
F(x j-1)<1-\left(\frac{k}{n}\right)<F(x j) \\
1-F 1(x j-1)
\end{gathered}
$$

Em que:

k é o número de empresas para o qual se deseja calcular a razão de concentração;

j é o intervalo de classe $(j=1,2, \ldots . J)$;

$C R_{k}$ é a razão de concentração; share;

$\mathrm{F}_{1}\left(\mathrm{x}_{\mathrm{j}}-{ }_{1}\right)$ é frequência acumulada da variável indicativa do market

$\mathrm{F}\left(\mathrm{x}_{\mathrm{i}}\right)$ é a distribuição de frequência do número de empresas por intervalo de classe.

O referido método permite calcular uma estimativa para a razão de concentração que varia entre uma fronteira inferior e um limite superior, sendo que a probabilidade do verdadeiro nível de concentração do mercado (caso fosse observado) estar contido neste intervalo é de 1 (um). A equação (3) permite estimar a fronteira inferior e a equação (5) determina o limite superior, enquanto a equação (4) estabelece o intervalo dos dados da frequência acumulada da variável indicativa do market share e da distribuição de frequência do número de empresas por intervalo de classe que serão aplicados na equação (3). O método também permite calcular uma estimativa pontual da razão de concentração, com elevado grau de precisão, que é dada pela exponencial da média dos logaritmos naturais das estimativas inferior e superior calculadas.

Segundo o paradigma E-C-D, há uma estreita relação entre o grau de concentração e a lucratividade, dado o argumento de que um mercado concentrado facilita a colusão de empresas, diminuindo a competição via preços (hipótese do poder de mercado). A existência de lucro econômico no longo prazo é um forte indício de poder de mercado, uma vez aceita a suposição de que em mercados competitivos a livre entrada de concorrentes elimina qualquer lucratividade em excesso sobre o custo de oportunidade do investimento de capital. Há um conjunto de variáveis estruturais explicativas do desempenho econômico de uma determina- 
da indústria, sendo que as medidas de performance de mercado mais usuais são os indicadores de lucro econômico ou a taxa de retorno sobre o investimento e a margem preço-custo (PCM). Os lucros econômicos são dados pela diferença entre as receitas e o custo de oportunidade de todos os insumos gastos no processo produtivo. Da mesma forma, quanto mais concentrada for uma indústria maior o seu poder de mercado e, por consequência, maior a sua rentabilidade medida por meio do percentual da margem preço-custo. (CHURCH; WARE, 2000)

A margem preço-custo - uma medida aproximada do índice de Lerner para performance de mercado - é definida como a diferença entre o preço e o custo marginal como proporção do preço. Dada a dificuldade em encontrar dados para mensurar o custo marginal das firmas, em geral, utiliza-se o custo variável médio em lugar do primeiro. Assim, a margem preço-custo pode ser calculada subtraindo das receitas de vendas o custo médio e dividindo o resultado pela receita, como é dado pela expressão (6):

$$
P C M=\frac{\text { Receita de Vendas }- \text { Custos Médios }}{\text { Receita de Vendas }}
$$

Contudo, conforme destacam Church e Ware (2000), pode haver problemas de erros de estimação associados à margem preço-custo, cuja extensão depende da taxa de retorno observada para a indústria, da taxa de depreciação do capital e da razão capital/receita.

A intensidade das barreiras à entrada é outro fator indicativo do poder de mercado em uma indústria específica, com reflexos na sua performance econômica. Estudos de organização industrial apontam para a diferenciação de produtos decorrente da preferência dos consumidores como uma fonte de barreiras à entrada. A diferenciação de produtos, que pode ocorrer por meio de propaganda e diferentes práticas de promoção de vendas, ajuda a criar impedimentos aos potenciais entrantes no mercado. Quando o custo com propaganda é elevado em relação ao faturamento, há receio por parte das firmas ingressantes de incorrer em pesados custos irrecuperáveis. Os consumidores, ao considerarem mais vantajoso adquirir um produto ofertado pelas firmas já existentes quando comparado a produtos similares oferecidos pelos novos concorrentes, obrigam a empresa entrante a estabelecer um preço mais baixo por seus produtos ou incorrer em gastos de vendas mais elevados, o que resultará em uma relação preço-custo (incluindo os custos de venda) desfavorável para a entrante em potencial.

Conforme destacam Possas et al. (1998), vários são os fatores que podem determinar a preferência dos consumidores pelas firmas 
já estabelecidas no mercado, tais como: i) lealdade ou fidelidade dos consumidores à marca já estabelecida (consumo conspícuo), impondo aos novos concorrentes despesas elevadas de vendas para tornar seu produto conhecido e aceito no mercado; ii) publicidade acumulada no tempo, que realça o valor da marca nas decisões de compra dos consumidores e ajuda a fidelizar os clientes, limitando o acesso ao consumidor para os novos concorrentes; iii) durabilidade e qualidade dos produtos, que acentuam a reputação das empresas estabelecidas, impondo ao novo concorrente gastos elevados com propaganda e marketing para convencer o consumidor das qualidades do novo produto; iv) redes de distribuição e assistência técnica sob controle das empresas estabelecidas, ou serviços adicionais associados aos produtos.

Assim, quanto mais diferenciado for o produto, na percepção dos consumidores, maior será a parcela do faturamento gasta em propaganda. Neste sentido, os gastos da construção civil com propaganda como proporção da receita bruta setorial pode ser um indicativo do grau de barreiras à entrada e um importante condicionante da estrutura de mercado no caso específico do segmento de construção de edificações.

\subsection{Fontes dos Dados}

Os dados usados nas estimativas da razão de concentração são provenientes do Cadastro Central de Empresas (CEMPRE), disponível no Banco de Dados Sidra (IBGE, 2008). As informações referem-se às empresas e às unidades locais formalmente constituídas que no ano de referência estavam ativas no Cadastro Nacional de Pessoa Jurídica, seja via declaração da RAIS ou em alguma das pesquisas econômicas do IBGE. Estão disponíveis no CEMPRE dados sobre número de empresas, unidades locais, pessoal ocupado total, pessoal assalariado e salários e outras remunerações, passíveis de desagregação nos diversos níveis da Classificação Nacional de Atividades Econômicas - CNAE - (IBGE, 1996) e também em diferentes níveis geográficos - Grandes Regiões, Unidades da Federação e Municípios.

As informações utilizadas para analisar as barreiras à entrada e estimar os indicadores de desempenho são extraídas da Pesquisa Anual da Indústria da Construção - PAIC (IBGE, 2005). As estatísticas usadas na caracterização geral da indústria de construção, tais como valor da produção, valor adicionado, valor das obras executadas, rendimento médio, distribuição espacial e nível de ocupação da mão de obra são extraídas da Pesquisa Anual da Indústria da Construção - PAIC (IBGE, 2005), do Sistema de Contas Nacionais do Brasil (IBGE, 2004), do Sistema de Contas Regionais (IBGE, 2004), da Pesquisa Nacional por Amostras 
em Domicílios - PNAD - (IBGE, 2006) e da matriz insumo-produto do macrossetor da construção em Minas Gerais (SILVA, 2006).

\section{Apresentação e Discussão dos Resultados}

\subsection{Concentração de Mercado na Construção Civil Mineira}

Para estimar a razão de concentração para a indústria da construção civil em Minas Gerais, foi utilizado o método proposto por McCloughan e Abounoori (2003), seguindo as equações (3), (4) e (5) anteriormente descritas. A razão de concentração foi calculada para o período de 1996-2005, considerando as 100 (cem) maiores empresas do setor no agregado e também para todos os grupos de atividades componentes, ${ }^{2}$ conforme a classificação 45 da Classificação Nacional de Atividades Econômicas - CNAE - (IBGE, 1996). Tomou-se como variável explicativa do market share o pessoal ocupado total. A opção pela variável pessoal ocupado em detrimento de outras variáveis monetárias (como valor da produção, valor das obras e serviços executados, receita bruta total etc.) para o cálculo da concentração de mercado, como sugere a literatura de organização industrial, justifica-se pela indisponibilidade de dados em termos de valor para todas as empresas de construção, mesmo que agregadas por grupos. A Pesquisa Anual da Indústria da Construção - PAIC - (IBGE), a maior fonte de dados desagregados sobre o setor, apresenta informações contábeis somente para as empresas de construção que empregam acima de cinco pessoas (totalizando apenas $27,5 \%$ do total dos estabelecimentos). Para a maioria absoluta das empresas de construção, que empregam menos que cinco pessoas, não há outro indicador disponível que não seja o pessoal ocupado. Outrossim, vale destacar que muitos estudos internacionais também recorrem ao mesmo procedimento, a exemplo de McCloughan (2004), Chiang, Tang e Leung (2001) e Sancilo et al. (2007). Além disso, como a concentração de mercado será calculada por grupos de atividades da construção, a heterogeneidade na absorção de mão de obra empregada pode ser uma boa proxy para demarcar a heterogeneidade intraindustrial. Os resultados encontrados são apresentados na Tabela 4.

2 Exceto para o segmento de aluguel de equipamentos de construção e demolição com operários, que registrou número de empresas e pessoal ocupado insuficientes para o cálculo da razão de concentração pelo método proposto, mesmo considerando-se apenas as 50 (cinquenta) maiores empresas. 
Tabela 4 - Cálculo do intervalo para CR (100) pelo Método MA Indústria da Construção - Minas Gerais

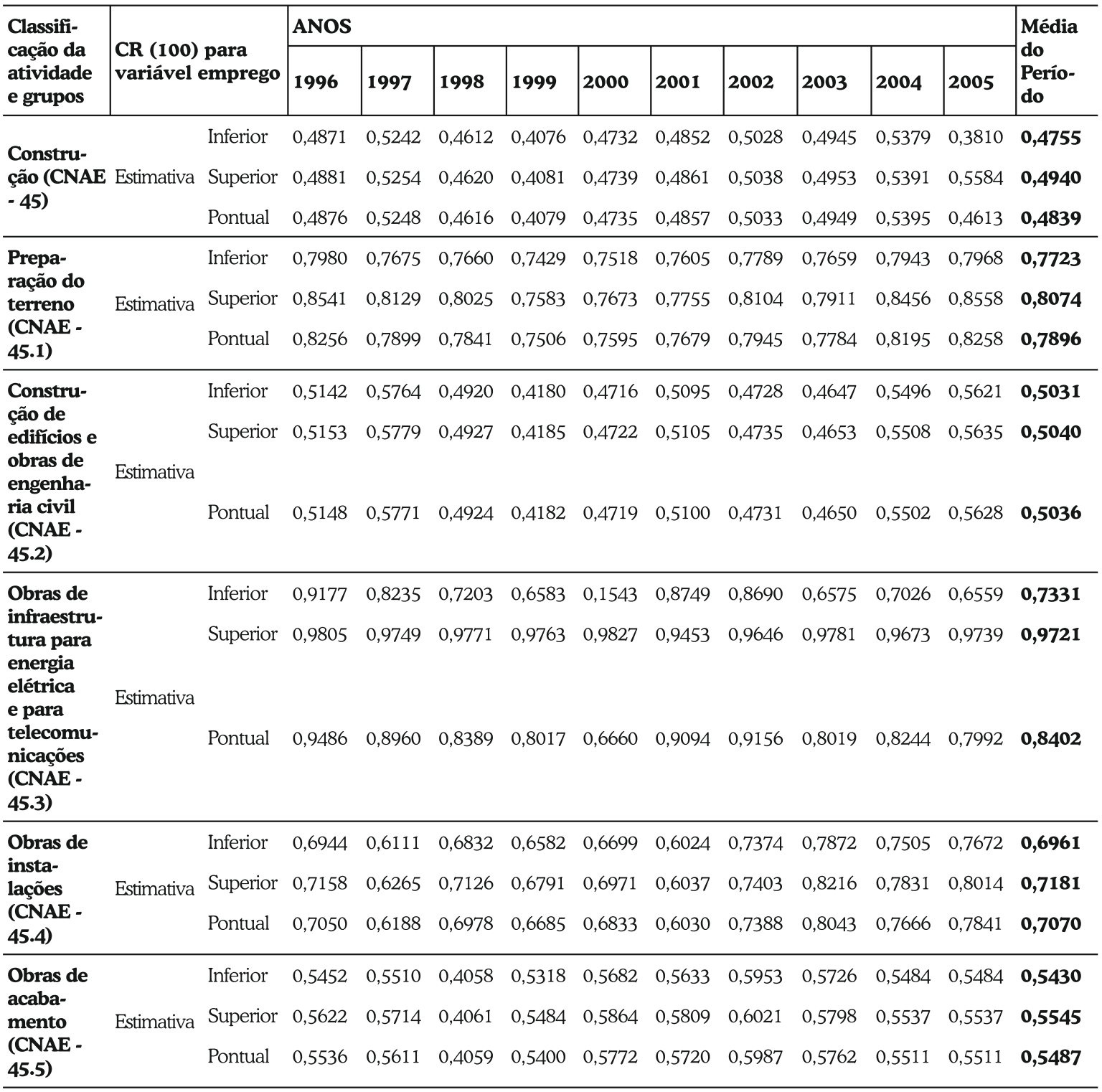

Fonte: Elaboração da autora a partir do Cadastro Central de Empresas - Banco de Dados Sidra - IBGE.

As estimativas indicam que o mercado da construção civil em Minas Gerais é bastante concentrado. Na média do período considerado, as 100 maiores empresas de construção mineiras ocuparam quase 50\% da mão de obra total do setor, nas três estimativas consideradas (inferior, superior e pontual). Em 1997 e 2004, anos de taxas de crescimento econômico setorial positivo, as razões de concentração ultrapassaram o patamar de $50 \%$, atingindo mais de $52 \%$. Este resultado é contrário ao que foi encontrado para a indústria da construção brasileira. Segundo estimativas de Teixeira (2009), os graus de concentração setorial ficaram próximos de $22 \%$, $25 \%$ e $23 \%$ nos limites inferior, superior e pontual, 
respectivamente, o que indica que a construção nacional tem uma estrutura industrial pouco concentrada, ao contrário da mineira, em se tratando da variável pessoal ocupado.

A proposição de elevada concentração industrial, no caso da construção mineira, sustenta-se, tanto avaliando o setor em seu conjunto como levando em conta os seus segmentos individualmente. Os grupos de atividade apresentam distinção entre si, no que diz respeito à concentração das 100 maiores empresas, mas prevalecem os indicadores de concentração elevados. Observam-se percentuais de concentração industrial acima de 50\% para todos os subsetores separadamente, cabendo ressaltar que as atividades de preparação do terreno e obras de infraestrutura para engenharia elétrica e para telecomunicações são excessivamente concentradas. As estimativas pontuais para os percentuais de concentração nestes dois segmentos de atividades foram de $79 \%$ e $84 \%$, respectivamente. Ou seja, as 100 maiores empresas nestes subsetores detêm uma elevada fatia do mercado no quesito ocupação da mão de obra. Nestes dois segmentos, há o predomínio de um número mais reduzido de estabelecimentos, conforme discutido no item 2.1, justificado talvez pela exigência maior de capital fixo para a iniciação das atividades no mercado. Estas atividades são capital-intensivas e exigem um elevado aporte inicial de recursos aplicados em máquinas e equipamentos e em meio de transporte, o que pode criar barreiras à entrada de novas firmas no mercado.

Os elevados índices de concentração industrial estimados podem sugerir não só que as empresas têm poder de mercado para estabelecer políticas de preços e vendas que lhes sejam favoráveis, mas também a existência de barreiras à entrada e diferenciação de produto, via maior capacidade de investimento em propaganda e marketing. A proposição de Concha-Amin e Aguiar (2006, p. 46) para o setor supermercadista brasileiro também é válida para o caso do segmento de edificações na indústria de construção civil. Por ser um setor multimercado,

[...] a noção de diferenciação do produto está mais relacionada à reputação da empresa, o que em grande parte é reflexo de seu tamanho e capacidade de despender em propaganda. Por isso, medidas de concentração poderiam dar indicações, ao mesmo tempo, de poder de mercado e do poder de diferenciação das empresas.

As estimativas de concentração na indústria de construção mineira contradizem as expectativas iniciais, já apontadas para o setor em nível nacional e também em outros países. A ideia de que a indústria construtora é fragmentada, composta por um grande número de pequenas 
firmas, com elevado grau de competição no mercado não pôde ser ratificada em se tratando da economia de Minas Gerais. Pelo contrário, tal indústria se mostrou bastante concentrada, com alto poder de mercado, cabendo atenção especial no caso das atividades de preparação do terreno e obras de infraestrutura para engenharia elétrica e para telecomunicações.

\subsection{Mercado do Produto e Mercado Geográfico Relevante para a Construção}

Uma característica peculiar da indústria de construção é a grande diversidade de seus produtos finais e serviços e a heterogeneidade em sua estrutura produtiva. Pela Classificação Nacional de Atividades Econômicas do Instituto Brasileiro de Geografia e Estatística (CNAE, 2004), a construção pode ser desagregada em seis grandes grupos de atividades: i) preparação do terreno; ii) construção de edifícios e obras de engenharia civil; iii) obras de infraestrutura para engenharia elétrica e para telecomunicações; iv) obras de instalações; v) obras de acabamentos e serviços auxiliares e vi) aluguel de equipamentos para construção e demolição com operários. Tendo em vista o vasto conjunto de atividades que o setor envolve, o mesmo pode ser considerado multiproduto, distinguindo-se em vários mercados de produtos finais e serviços associados à construção civil.

Na perspectiva da estrutura de oferta, há um certo grau de flexibilidade entre os diferentes segmentos de atividades, dado que as empresas de construção não estão limitadas ao segmento em que atuam. Há sobreposição das atuações dos estabelecimentos em vários segmentos. De fato, as grandes empresas de construção nacional atuam simultaneamente em várias atividades, considerando a mobilidade de ativos - mão de obra e equipamentos - que podem ser facilmente terceirizados ou mesmo fazerem parte do ativo da empresa. No entanto, a sobreposição das atividades fica mais restrita às subatividades componentes de cada grande grupo.

No que tange ao aspecto geográfico, o mercado relevante para a indústria da construção brasileira é definido como todo território nacional, haja vista a forte penetração de suas atividades nas cinco regiões geográficas e em todas as unidades da federação. Embora o produto final da construção seja imóvel e a demanda dos serviços associados à construção seja localmente limitada, há sobreposição horizontal de obras e serviços, uma vez que os principais ativos (mão de obra e equipamentos) podem ser terceirizados. Com isso, há facilidade de expansão 
da base territorial por parte das empresas de construção, em especial, quando consideram-se as empresas de grande e médio portes.

\subsection{Diferenciação de Produtos e Barreiras à Entrada de Novos Concorrentes}

Por ser um setor multimercado, com diferentes segmentos produzindo uma grande diversidade de produtos e serviços finais, a indústria da construção exibe certa homogeneidade nos bens finais ofertados, se esses forem tomados isoladamente, ou seja, quando comparados entre os produtores de um mesmo segmento.

Ao mensurar a relação entre barreiras à entrada e concentração industrial, é importante ter em mente o mercado relevante da indústria estudada. No caso da indústria da construção, o mercado relevante é definido como todo o território nacional, dada a enorme capilaridade e forte penetração das suas atividades nas cinco regiões geográficas e em todas as unidades da federação.

As despesas com propaganda podem sinalizar vantagens das firmas estabelecidas no mercado, no que concerne a preferência dos consumidores, influência nas decisões de compra e diferenciação entre as firmas já estabelecidas, funcionando como uma fonte de barreiras à entrada. A proporção dos gastos com propaganda na receita bruta total dos vários segmentos da indústria da construção pode ser um indicativo das condições estruturais neste mercado.

Os dados da Tabela 5 confirmam as expectativas iniciais, indicando que a construção civil é um setor com baixo grau de diferenciação de produtos e serviços finais, medido pelo reduzido investimento em propaganda e marketing. Dentre os segmentos componentes, a construção de edifícios é o que apresenta a maior proporção de gastos com propaganda no total da receita bruta, mas o percentual é ainda insignificante, ficando abaixo de $1 \%(0,81 \%$ na média de 2005 a 2003). Portanto, não se pode induzir que há barreiras à entrada associadas à diferenciação de produtos nas atividades construtivas. Contudo, embora o setor não esteja sujeito à diferenciação de produtos e serviços finais, há outras fontes de barreiras à entrada importantes e que podem justificar os elevados graus de concentração das atividades construtivas em Minas Gerais. 
Tabela 5 - Receita bruta total e despesas com propaganda das empresas de construção, segundo grupos e classes de atividades - Brasil - valor médio de 2005 a 2003.

\begin{tabular}{|c|c|c|c|}
\hline \multirow{3}{*}{ Grupos e classes de atividades } & \multicolumn{2}{|c|}{ Valor médio 2005-2003 } & \multirow{3}{*}{\begin{tabular}{|l} 
Porção de (2) \\
em (1)
\end{tabular}} \\
\hline & Receita & Despesas & \\
\hline & \multicolumn{2}{|c|}{ em $R \$ 1.000$} & \\
\hline Total das empresas & 97.821 .358 & 329.704 & 0,34 \\
\hline Empresas até 4 pessoas ocupadas & 10.026 .959 & 5.524 & 0.06 \\
\hline Empresas entre 5 e 29 pessoas ocupadas & 14.583 .110 & 47.498 & 0,33 \\
\hline Preparação do terreno & 1.167 .883 & 4.155 & 0,36 \\
\hline Construção de edifícios e obras de engenharia civil & 10.569 .730 & 37.714 & 0,36 \\
\hline $\begin{array}{l}\text { Obras de infraestrutura para engenharia elétrica } \\
\text { e para telecomunicações }\end{array}$ & 434.053 & 173 & 0,04 \\
\hline Obras de instalações & 1.449 .605 & 3.994 & 0,28 \\
\hline Obras de acabamento & 807.828 & 1.360 & 0,17 \\
\hline $\begin{array}{l}\text { Aluguel de equipamentos de construção e } \\
\text { demolição com operador }\end{array}$ & 154.010 & 102 & 0,07 \\
\hline Empresas com 30 ou mais pessoas ocupadas & 73.211 .289 & 276.682 & 0,38 \\
\hline Preparação do terreno & 3.964 .830 & 11.783 & 0,30 \\
\hline Construção de edifícios e obras de engenharia civil & 52.046 .199 & 237.071 & 0,46 \\
\hline $\begin{array}{l}\text { Edificações (residenciais, industriais, comerciais } \\
\text { e de serviços) }\end{array}$ & 24.803 .472 & 200.149 & 0,81 \\
\hline Obras viárias & 13.851 .641 & 21.471 & 0,16 \\
\hline Obras de arte especiais & 2.787 .884 & 4.746 & 0,17 \\
\hline Obras de montagem & 3.008 .634 & 2.282 & 0,08 \\
\hline Obras de outros tipos & 7.594 .567 & 8.423 & 0,11 \\
\hline $\begin{array}{l}\text { Obras de infraestrutura para engenharia elétrica } \\
\text { e para telecomunicações }\end{array}$ & 8.920 .405 & 10.776 & 0,12 \\
\hline Obras de instalações & 5.937 .497 & 12.109 & 0,20 \\
\hline Obras de acabamento & 1.779 .992 & 4.396 & 0,25 \\
\hline $\begin{array}{l}\text { Aluguel de equipamentos de construção } \\
\text { e demolição com operador }\end{array}$ & 562.367 & 546 & 0,10 \\
\hline
\end{tabular}

Fonte: Elaboração da autora a partir da Pesquisa Anual da Indústria da Construção 2005, IBGE.

${ }^{*}$ ) Inclusive as receitas de outras atividades (serviços, indústria etc).

É difícil estabelecer preferências entre as obras executadas pelo segmento de preparação de terreno; as obras de engenharia civil; as obras de infraestrutura para engenharia elétrica e para telecomunicações; as obras de instalações e acabamentos e aluguel de equipamentos de construção e demolição com operários. Nestes casos, a diferenciação 
ocorre mais entre as próprias firmas, muito em função do tamanho e da experiência no mercado. Em geral, empresas maiores possuem uma melhor rede de relacionamentos com distribuidores; detêm os melhores fornecedores; têm mais experiência técnica, profissionais mais qualificados e equipamentos e maquinários mais modernos, bem como oferecem menores preços e melhores condições de venda, porque têm acesso mais facilitado a financiamentos ou detêm mais recursos próprios. Conforme coloca Finkel (1997, p. 37),

[...] the scale of major construction projects often presents itself as a barrier to small and mid-sized firms, as it may require access to large work force and a proven track record in a particular aspect of the industry. Capital requirements in terms of tools and material further reduce the number of firms capable of entering the market.

Além disso, nos segmentos específicos de obras de engenharia civil e obras de infraestrutura para engenharia elétrica e para telecomunicações, como a demanda é, na grande maioria, proveniente do setor público, a concorrência se dá através do menor preço e/ou da melhor técnica, conforme a lei de licitações (Lei 8.666/93). E, nesses casos, as maiores empresas quase sempre possuem vantagens relativas significativas.

Cabe ressaltar, ainda, que nos segmentos de preparação de terreno; obras de engenharia civil; obras de infraestrutura para engenharia elétrica e para telecomunicações; e aluguel de equipamentos de construção e demolição com operários, há exigência de investimentos iniciais elevados - associada à relação capital/produto e ao alto custo de aquisição das máquinas e equipamentos - para viabilizar as atividades. Isto constitui em si forte barreira à entrada. As empresas já estabelecidas, em geral, têm acesso mais facilitado a fundos para investimento a custos inferiores àqueles disponíveis para as entrantes. Esta vantagem das firmas existentes cresce em proporção ao montante de capital requerido para o investimento inicial da nova empresa, que será tanto maior quanto maior for a escala eficiente mínima de entrada em termos absolutos (o que resulta em uma deseconomia de escala para a empresa entrante) e, quanto maior for o grau de diferenciação de produto vigente, que pode resultar na necessidade de um elevado gasto inicial com esforço de vendas. (POSSAS et al., 1998)

Segundo dados da PAIC (IBGE, 2005), para o ano de 2004, as atividades de preparação de terreno responderam com mais de $14 \%$ dos itens ativo imobilizado - máquinas e equipamentos e meio de transporte - na composição da estrutura de investimentos da construção nacional. 
Estes dois itens sozinhos corresponderam a 37\% do total do ativo imobilizado do segmento, o que é um bom indicativo do peso dos mesmos no total dos investimentos deste segmento em particular. Para efeito de comparação, os mesmos percentuais para o segmento de obras de infraestrutura para engenharia elétrica e para telecomunicações foram $7 \%$ e $27 \%$, respectivamente.

O segmento mais exposto à preferência dos consumidores é mesmo a construção de edifícios, porque produz produtos e serviços finais que podem ser diferenciados, além da reputação do ofertante, em termos de sua qualidade, do design dos projetos e outros atributos mais subjetivos. Neste segmento em particular, pode prevalecer a lealdade ou fidelidade dos consumidores a uma empresa já estabelecida e reconhecida no mercado pela qualidade dos materiais empregados e acabamentos das obras executadas; durabilidade da construção; serviços oferecidos no pós-venda, bem como pela pontualidade no prazo de entrega do projeto, ou ainda por oferecer melhores condições de negociação no valor de venda dos imóveis. Esta ocorrência está também muito associada ao valor final do produto, sendo mais acentuada em produtos e serviços direcionados às classes de renda mais elevada, em que há uma maior preocupação e exigência com a qualidade do bem ofertado no mercado.

Empresas maiores possuem vantagens relativas em termos de melhores fornecedores; mais experiência técnica; profissionais mais qualificados; equipamentos mais modernos e projetos com maior escala de produção. Todos esses fatores ajudam a compor as barreiras à entrada decorrentes de vantagens absolutas de custo, que ocorrem quando as empresas estabelecidas possuem em maior grau determinados fatores produtivos, que podem ser recursos humanos mais qualificados; tecnologias específicas; controle do suprimento de matérias-primas através da integração vertical, contratos exclusivos ou compra em grandes volumes; menor custo de obtenção de capital, resultante de imperfeições no mercado de capitais ou da maior facilidade no uso de fundos próprios para financiar seus investimentos. Tais vantagens permitem às firmas estabelecidas produzir, com a mesma escala de produção de um entrante potencial, a um custo mais baixo. E a existência destas barreiras à entrada ajuda a justificar as elevadas concentrações de mercado encontradas para as atividades de construção em Minas Gerais.

\subsection{Desempenho Econômico da Construção Civil Mineira}

A PAIC (IBGE, 2005) apresenta uma aproximação da produtividade das empresas de construção, ao relacionar o valor das obras e/ou ser- 
viços da construção com o pessoal ocupado. Os resultados, expressos na Tabela 6, mostram que a produtividade da indústria de construção em Minas Gerais está bem aquém da média nacional e também da média da região Sudeste, além de apresentar perda relativa nos dois anos analisados. A variação da produtividade estadual frente à média nacional caiu quase 30\% em 1996 e aproximadamente $21 \%$ em 2005. Isto pode dar indicações de que as empresas de construção em Minas Gerais têm apresentado desempenho produtivo inferior relativamente à média dos estados da federação.

Tabela 6 - Produtividade nas empresas de construção, segundo Grandes Regiões e Unidades da Federação - 1996 e 2005

\begin{tabular}{|c|c|c|c|c|}
\hline \multirow{3}{*}{$\begin{array}{l}\text { Grandes Regiões } \\
\text { e Unidades da } \\
\text { Federação }\end{array}$} & \multicolumn{4}{|c|}{ Produtividade nas empresas de construção } \\
\hline & \multicolumn{2}{|c|}{ em $(R \$ 1.000,00)$} & \multicolumn{2}{|c|}{ var.\% frente à média nacional } \\
\hline & 1996 & 2005 & 1996 & 2005 \\
\hline Brasil & 48,80 & 73,50 & - & - \\
\hline Norte & 47,40 & 82,60 & $-2,80$ & 12,40 \\
\hline Nordeste & 38,20 & 60,10 & $-21,80$ & $-18,20$ \\
\hline Sudeste & 51,50 & 75,60 & 5,60 & 2,90 \\
\hline Minas Gerais & 34,40 & 57,80 & $-29,40$ & $-21,30$ \\
\hline Espírito Santo & 44,00 & 67,30 & $-9,80$ & $-8,40$ \\
\hline Rio de Janeiro & 51,30 & 79,60 & 5,20 & 8,30 \\
\hline São Paulo & 59,10 & 84,30 & 21,00 & 14,70 \\
\hline Sul & 50,70 & 76,40 & 4,00 & 4,00 \\
\hline Centro-Oeste & 47,90 & 80,10 & 4,20 & $-6,40$ \\
\hline
\end{tabular}

Fonte: Elaboração da autora a partir de dados da PAIC - IBGE (2005).

Os dados contidos na Tabela 7 também ajudam na análise do desempenho da construção mineira entre 2002 e 2005, embora não seja possível obter tais informações desagregadas por subsetor de atividades da construção mineira. ${ }^{3} \mathrm{O}$ valor adicionado pelas empresas de construção formais com cinco ou mais pessoas ocupadas, medido como a diferença entre o valor da produção e o consumo intermediário, é usado como uma proxy para mensurar a eficiência produtiva. A evolução do valor adicionado (deflacionado pelo IGP-DI) indica que a produtividade do setor foi crescente e mais que dobrou entre os anos analisados, apesar de ter caído o número de unidades empresariais. O mesmo aconteceu com o valor das obras e/ou serviços da construção. As receitas líquidas

3 Estes dados desagregados por grupos de atividades da construção só estão disponíveis na Pesquisa da Indústria da Construção, PAIC - IBGE (2005) para o total Brasil. 
do setor (igualmente deflacionadas pelo IGP-DI) subiram próximo de $87 \%$ no período, atingindo quase $\mathrm{R} \$ 10,4$ bilhões em 2005. É interessante notar que a proporção da receita líquida das empresas de construção em Minas Gerais no total da receita líquida da construção nacional cresceu no período, a despeito da participação dos estabelecimentos mineiros ter caído no número total dos estabelecimentos de construção para o conjunto do país. Estes resultados estão de acordo com o elevado grau de concentração encontrado para a construção civil em Minas Gerais, porque as maiores empresas são as que possuem a maior produtividade. O ganho de eficiência pode estar associado ao tamanho das empresas. Conforme esclarece a PAIC de 2006 (IBGE),

[...] no que tange à produtividade, as empresas com 1000 ou mais pessoas ocupadas registraram um valor $27,8 \%$ superior ao resultado alcançado pelo setor, enquanto o grupo de empresas com o pessoal ocupado entre 250 e 999 pessoas ficou abaixo em 8,6\%. Já no conjunto das pequenas empresas, que têm pessoal ocupado entre 40 e 249 pessoas, a produtividade ficou 14,4\% abaixo da média do setor. Dessa forma, observa-se um aumento gradativo da produtividade à medida que aumenta o porte de empresa; uma possível explicação para esta relação entre produtividade e tamanho de empresa é que as grandes, que têm um volume de capital mais elevado, desenvolvem estruturas administrativas mais eficientes; têm mais facilidades de obter financiamentos e maior possibilidade de acesso a recursos provenientes dos investidores de bolsa de valores; além de maior capacidade de inovar em seus processos produtivos; etc.

Pode-se calcular a margem preço-custo (PCM) para a indústria da construção agregada, utilizando a receita bruta total como proxy para a receita de vendas e o total de custos e despesas como proxy para os custos médios das atividades, conforme apresentado no final da Tabela 7. A PCM pode ser tomada como um indicador de lucratividade, ou mesmo, como um indicador aproximado de mark-up, servindo para captar o poder de mercado (em termos de preços) exercido pelas empresas do setor. Em 2005, a margem preço-custo estimada para o conjunto das atividades foi de $12,6 \%$ e, embora tenha apresentado queda em relação ao ano anterior, houve crescimento da margem de $31 \%$ entre 2002 e 2005. Este resultado está de acordo com a maior concentração observada no setor. 
Tabela 7 - Dados gerais das empresas de construção, com 5 ou mais pessoas ocupadas - Minas Gerais - 2002 a 2005

\begin{tabular}{|c|c|c|}
\hline Variável & Ano & \\
\hline \multirow{4}{*}{ Número de empresas (Unidade) } & 2002 & 3.598 \\
\hline & 2003 & 3.481 \\
\hline & 2004 & 3.292 \\
\hline & 2005 & 3.182 \\
\hline \multirow{4}{*}{ Total de custos e despesas (Mil Reais) } & 2002 & 6.763 .555 \\
\hline & 2003 & 6.861 .830 \\
\hline & 2004 & 10.611 .094 \\
\hline & 2005 & 9.842 .650 \\
\hline \multirow{4}{*}{ Receita bruta total (Mil Reais) } & 2002 & 7.481 .023 \\
\hline & 2003 & 7.804 .556 \\
\hline & 2004 & 12.310 .570 \\
\hline & 2005 & 11.260 .619 \\
\hline \multirow{4}{*}{ Receita líquida (Mil Reais) } & 2002 & 7.014 .061 \\
\hline & 2003 & 7.324 .245 \\
\hline & 2004 & 11.561 .647 \\
\hline & 2005 & 10.481 .884 \\
\hline \multirow{4}{*}{$\begin{array}{l}\text { Valor das obras e/ou serviços da construção } \\
\text { (Mil Reais) }\end{array}$} & 2002 & 6.927 .724 \\
\hline & 2003 & 7.468 .509 \\
\hline & 2004 & 11.833 .790 \\
\hline & 2005 & 11.027 .764 \\
\hline \multirow{4}{*}{ Valor adicionado (Mil Reais) } & 2002 & 3.626 .515 \\
\hline & 2003 & 3.870 .936 \\
\hline & 2004 & 6.201 .498 \\
\hline & 2005 & 5.878 .529 \\
\hline \multirow{4}{*}{ Margem preço-custo (PCM) em \% } & 2002 & $9,59 \%$ \\
\hline & 2003 & $12,08 \%$ \\
\hline & 2004 & $13,81 \%$ \\
\hline & 2005 & $12,59 \%$ \\
\hline
\end{tabular}

Fonte: Elaboração da autora a partir de dados da PAIC - IBGE (2005).

A análise das variáveis usadas para medir o desempenho econômico da indústria da construção mineira parece compatível com os dados estimados para a concentração de mercado. As altas razões de concentração encontradas, tanto para o setor no agregado quanto para as atividades individualmente, estão de acordo com a evolução positiva 
e significativa dos indicadores de desempenho econômico setorial produtividade e lucratividade. Parece haver uma relação direta entre uma estrutura de mercado excessivamente concentrada e com alta participação no market share (medida pela variável emprego) e uma elevada eficiência produtiva e lucratividade.

\section{Considerações Finais}

O estudo procurou apresentar uma visão geral do setor de construção em Minas Gerais a partir dos anos de 1990, destacando sua importância para a economia estadual. Uma característica marcante da indústria construtiva mineira é a elevada parcela de contribuição para o PIB da construção nacional e também para a composição do produto estadual. Em termos de valor adicionado, na média de 1990-2004, o setor mineiro ocupou o segundo lugar no ranking da construção nacional e contribuiu com 11\% para o PIB de Minas Gerais. Estes percentuais a qualificam como uma atividade relevante que merece atenção especial por parte dos formuladores de políticas públicas locais.

A indústria de construção mineira, tomada em seu conjunto ou desagregada por subsetores componentes, é uma atividade com papel estratégico na geração de emprego e massa salarial na economia mineira. Esta característica, por si só, torna o setor atrativo do ponto de vista de políticas sociais de ampliação de emprego e renda.

Em quase todos os países, as autoridades governamentais (centrais e locais) têm importante influência no setor de construção, através de várias maneiras, mas principalmente por meio das políticas econômicas que interferem na taxa de juros, mas condições de crédito, nível dos gastos públicos, na carga tributária e na regulação dos bens públicos. Em nível nacional, cabe um alerta às autoridades governamentais, no sentido de criar ações que incentivem a indústria da construção, que vem perdendo espaço para outras atividades e atingindo níveis críticos de crescimento econômico nos últimos anos, o que pode comprometer o desenvolvimento sustentável do Brasil nos médio e longo prazos. No tocante ao estado de Minas Gerais, as autoridades locais deveriam prestar mais atenção ao elevado efeito multiplicador de emprego e renda do setor. Este efeito positivo pode ser usado em benefício de toda a sociedade, paralelamente ao aumento do bem-estar econômico-social. Por suas características específicas, o setor poderia ser usado para impulsionar um novo ciclo de desenvolvimento no estado de Minas Gerais.

No que concerne à concentração de mercado, o setor de construção mineira mostrou-se excessivamente concentrado, o que pode ser um indicativo de baixo grau de competição entre as empresas existen- 
tes. Uma composição estrutural muito concentrada pode acarretar em práticas empresariais tácitas em termos de fixação de preços, política de vendas e qualificação do produto, que sejam desfavoráveis para os consumidores. Além disso, pode afetar também a estrutura de custos do setor, prevenindo investimentos redutores dos mesmos. E tais comportamentos empresarias podem repercutir no desempenho econômico do setor, medido tanto em termos da obtenção de lucros excessivos quanto do sucesso de um mercado em produzir benefícios para o consumidor e a sociedade em geral. $O$ estudo mostrou que a lucratividade do setor tem crescido a taxas significativas nos últimos anos e que a eficiência produtiva da construção mineira também percorre uma trajetória ascendente, apesar de a variação da produtividade da construção estadual ter caído frente à média nacional entre 1996 e 2005. É importante um acompanhamento constante e mais de perto do setor da construção mineira por parte das autoridades governamentais. $\mathrm{O}$ conhecimento da organização industrial do setor é de validade tanto para a atuação das empresas já existentes quanto para as potencialmente entrantes no mercado, como também para a intervenção governamental por meio de políticas públicas mais adequadas à realidade das atividades construtivas locais. Uma estrutura muito concentrada pode sugerir que há ineficiências na alocação de recursos, com prejuízo para os consumidores e a sociedade como um todo.

Por fim, cabe destacar que, apesar do modelo E-C-D ser muito usado para descrever a organização industrial e monitorar as mudanças econômicas estruturais, há percalços no seu uso como instrumental de análise econômica. Os modelos de inspiração neoschumpeteriana questionam as proposições básicas do paradigma E-C-D, argumentando que, nem sempre nem todo poder de mercado da empresa tomará a forma de preços ou mark-ups mais elevados. Além disso, a hipótese de que estruturas mais concentradas devem ter como contrapartida desempenhos produtivos menos satisfatórios que os associados a mercados mais concorrenciais desconsidera que estruturas mais concentradas e com elevadas barreiras à entrada podem refletir antes as necessidades técnicas do setor. O senão é que há ainda debates não conclusivos sobre a dicotomia entre organizações e instituições, obscurecendo as análises dos neoschumpeterianos que incorporam o conceito de instituições no exame da concorrência. A Teoria dos Mercados Contestáveis também pode ser uma opção interessante para estimular a competição nas indústrias de infraestrutura, em que economias de escala e de escopo são instrumentos de vantagens competitivas das grandes firmas sem, contudo, representar grandes prejuízos para o desempenho social. Nestes casos, o modelo de mercados contestáveis ajudaria os órgãos 
reguladores a desenhar normas a fim de garantir preços próximos ao nível do bem-estar social.

Além disso, estudos posteriores poderiam centrar as atenções na estrutura de produção da construção civil mineira, investigando a relação entre a produtividade e o tamanho de suas empresas, bem como lançando luzes sobre as razões para a elevada informalidade prevalecente no setor.

\section{Referências}

AGUIAR, D. R. D. A política de defesa da concorrência no Brasil: uma introdução. In: BRAGA, M. J.; AGUIAR, D. R. D.; TEIXEIRA, E. L. (Ed.). Defesa da concorrência e poder de mercado no agronegócio. Viçosa, MG, 2005.

BAIN, J. S. Industrial organization. New York: John Wiley, 1959.

BRUMER, S. Estrutura, conduta e desempenho de mercado da indústria metal-mecânica gaúcha. Ed. Fundação de Economia e Estatística, 1977.

CARNEIRO, D. D.; VALPASSOS, M. V. F. Financiamento à habitação e instabilidade econômica: experiências passadas, desafios e propostas para a ação futura. Rio de Janeiro: FGV, 2003.

CHAVES, M. A indústria da construção no Brasil: desenvolvimento, estrutura e dinâmica. 1985. Dissertação (Mestrado) - Instituto de Economia Industrial, Universidade Federal do Rio de Janeiro, Rio de Janeiro, 1985.

CHIANG, Y. H.; TANG, B. S.; LEUNG, W. Y. Market Structure of the Construction Industry in Hong Kong. Construction Management and Economics, v. 19, n. 7, p. 675-687, 2001.

CHURCH, J.; WARE, R. Identifying and measuring market power. In: Industrial organization: a strategic approach, Chapter 12. San Francisco: McGraw-Hill, 2000.

CONCHA-AMIN, M.; AGUIAR, D. R. D. Concentração industrial, fusões e turnover no setor supermercadista brasileiro. Gestão E Produção, v. 13, n. 1, p. 45-56, jan.-abr. 2006.

FAGUNDES, J.; PONDÉ, J. Barreiras à entrada e defesa da concorrência: notas introdutórias. Texto para Discussão n. 1, 1998.

FUNDAÇÃO GETÚLIO VARGAS - FGV. O macrossetor da construção. Rio de Janeiro: IBRE, 2005.

FUNDAÇÃO JOÃO PINHEIRO - FJP. Diagnóstico nacional da indústria da construção civil. 20v., Belo Horizonte, 1984.

. Desenvolvimento da indústria da construção em Minas Gerais: impacto na evolução tecnológica e na qualificação da força de trabalho. Belo Horizonte: FJP, 1992.

. Competitividade na indústria da construção em Minas Gerais: estratégias de sobrevivência no mercado. Belo Horizonte: FJP, 1993. [Proposta técnica e orçamentária]

. Um novo marco do desenvolvimento da indústria da construção: os abalos da crise sobre o setor. Belo Horizonte: FJP, 1993. 
FINKEL, G. The economics of the construction industry. M. E. Sharpe, Armonk: New York, London, England, 1997.

HAGUENAUER, L. Competitividade: conceitos e medidas. Texto para Discussão, n. 211. Rio de Janeiro, 1989.

HILLEBRANDT, P. M. Economic theory and the construction industry. 3 ed. Palgrave, 2000.

HIRSCHMAN, A. O. Estratégia do desenvolvimento econômico. Rio de Janeiro: Fundo de Cultura, 1961.

INSTITUTO BRASILEIRO DE GEOGRAFIA E ESTATÍSTICA - IBGE. Sistema de contas nacionais: Brasil 2004. Rio de Janeiro: IBGE, 2004.

. Cadastro Central de Empresas. Banco de Dados Sidra. Rio de Janeiro: IBGE, 2008. 2005 .

. Pesquisa Anual da Indústria da Construção: PAIC, 2005. Rio de Janeiro: IBGE,

. Pesquisa Nacional por Amostras em Domicílios: PNAD, 2002-2006. Rio de Janeiro: IBGE, 2006.

Sistema de Contas Regionais, 2004. Coordenação de Contas Regionais. Rio de Janeiro: IBGE, 2004. 2004.

Classificação Nacional de Atividades Econômicas - CNAE. Rio de Janeiro: IBGE,

Economia Informal Urbana. Rio de Janeiro: IBGE, 2003.

KUPFER, D.; HASENCLEVER, L. (Org.). Estrutura de mercado e inovação. In: Economia industrial: fundamentos teóricos e práticos no Brasil. Rio de Janeiro: Elsevier, 2002.

KUPFER, D. Padrões de concorrência e competitividade. Texto para Discussão, n. ${ }^{\circ} 265$, Rio de Janeiro, 1992. Anais do XX Encontro Nacional da ANPEC, Campos do Jordão, 1992.

LEAN, C. S. Empirical tests to discern linkages between construction and other economic sector in Singapore. Construction Management and Economics. v. 19, n. 4, p. 355-363, 2001

LIBRELOTTO, L. I.; FERROLI, P. C. M.; RADOS, G. V. Caracterização da sustentabilidade nas empresas de construção civil. ENCONTRO NACIONAL DE ENGENHARIA E PRODUÇÃO (ENEGEP), n. 23, Ouro Preto, Anais..., Ouro Preto, 2003.

MARQUES, P. V. Contribuição ao estudo da organização agroindustrial: o caso da indústria de frango de corte no estado de São Paulo. Scientia Agricola, Piracicaba, v. 51, n. 1, p. 8-16, jan./abr. 1994.

MARTIN, S. Industrial economics: economic analysis and public policy. 2 ed. New Jersey: Prentice Hall, 1993.

MASON, E. S. Price and production policies of large-scale enterprise. The American Economic Review, v. 29, n. 1, p. 61-74, mar. 1939.

MCCLOUGHAN, P.; ABOUNOORI, E. How to estimate market concentration given grouped data. Applied Economics, v. 35, n. 8, p. 973-983, 2003.

MCCLOUGHAN, P. Construction sector concentration: evidence from Britain. Construction Manegement and Economics, v. 22, n. 9, p. 979-990, nov. 2004. 
MYERS, D. Construction economics: a new approach. London: Spon Press, 2004.

OFORI, G. The construction industry: aspects of its economics and management. Singapore: Singapore University Press, 1990.

POLENSKE, K. R.; SIVITANIDES, P. Linkages in the construction sector. In: The annals of regional science. Cambridge, MA, USA: MIT, jul. 1989.

POSSAS, M.; FAGUNDES, J.; PONDÉ, J. L. Defesa da concorrência e regulação de setores de infraestrutura em transição. Dez. 1998. [Artigo aprovado para a ANPEC].

RESENDE, M. Medidas de concentração industrial: uma resenha. Análise Econômica, Porto Alegre, v. 12, n. 21 e 22, p. 24-33, mar./set. 1994.

SANCILIO, S.; DIBARI, G.; COSTANTINO, N. A multinational comparison of concentration ratios in the construction market. Worcester, USA: Worcester Polytechnic Institute, p. 331-339, jun. 2007.

SCHERER, F. M. Industrial market structure and economic performance. Chicago: Rand McNallY College, 1970.

SCHERER, F. M.; ROSS, D. Industrial market structure and economic performance. 3 ed. Boston: Houghton Mifflin Company, 1990.

SCHMIDT, C. A. J.; LIMA, M. A. Índices de Concentração. Documento de Trabalho, n. 13, Ministério da Fazenda, Brasília, mar. 2002.

SILVA, A. B. O. Matriz do macrossetor da construção em Minas Gerais (1996) e no Brasil (2002). Elaborada em convênio com a Câmara da Indústria da Construção (CIC) da Federação das Indústrias de Minas Gerais (FIEMG). Belo Horizonte, abr. 2006.

. O cluster da construção em Minas Gerais e as práticas de colaboração e de gestão de conhecimento: um estudo de das empresas da RMBH (MG). 2007. Tese (Doutorado) - Escola de Ciência da Informação, Universidade Federal de Minas Gerais, Belo Horizonte, 2007.

SYLOS-LABINI, P. Oligopólio e Progresso Técnico. 2 ed. Rio de Janeiro: Forense Universitária, 1984.

TEIXEIRA, L. P. A indústria de construção brasileira sob a ótica da demanda efetiva. 2009. Tese (Doutorado em Economia Aplicada) - Universidade Federal de Viçosa, Viçosa, 2009 .

TEIXEIRA, L. P.; CARVALHO, F. M. A. A construção civil como instrumento do desenvolvimento da economia brasileira. Revista Paranaense de Desenvolvimento, Curitiba, n. 109, jul./dez. 2005.

TONER, P. Changes in industrial structure in the australian construction industry: causes and implications. The Economic and Labour Relations Review, v. 11, p. 291-307, 2000.

WORL BANK. The construction industry: issues and strategies in developing countries. Washington, DC: World Bank, 1984.

ZEIDAN, R. M. Robustez dos modelos da New Empirical Industrial Organization (NEIO) com aplicação ao mercado brasileiro de cimento. Ensaios sobre Poder de Mercado. Rio de Janeiro: IE/UFRJ, mar. 2005.

Recebido: 06/04/2009.

Aceito: 13/11/2009. 